\title{
Adıgüzel Baraj Gölü’nde (Denizli/Türkiye) Deterjan, Fosfat, Bor ve Ağır Metal Kirliliğinin Belirlenmesi
}

\author{
Orkide MINARECI' ${ }^{1}$, Murat ÇAKIR ${ }^{2}$
}

ÖZET: Bu çalışma Adıgüzel Baraj Gölü’ndeki deterjan, fosfat, bor ve ağır metal kirliliğini belirlemek amacıyla yapılmıştır. Ortalama anyonik deterjan, fosfat, bor, bakır, nikel, krom ve kurşun konsantrasyonları, sırasıyla $0.235 \mathrm{mg} \mathrm{L}^{-1}, 0.009 \mathrm{mg} \mathrm{L}^{-1}, 0.659 \mathrm{mg} \mathrm{L}^{-1}, 0.0048 \mathrm{mg} \mathrm{L}^{-1}, 0.0170 \mathrm{mg} \mathrm{L}^{-1}, 0.0016 \mathrm{mg} \mathrm{L}^{-1}, 0.0002 \mathrm{mg} \mathrm{L}^{-1}$ bulunmuştur. Bu değerler "Kıta İçi Su Kaynaklarının Sınıflarına Göre Kalite Kriterleri” ile karşıllaştırılmıştır. Adıgüzel Baraj Gölü anyonik deterjan parametresi açısından II. sınıf (az kirlenmiş su), fosfat, bor ve ağır metal parametreleri açısından I. sınıf (kirlenmemiş su) olarak sınıflandırılmıştır.

Anahtar kelimeler: Adıgüzel Baraj Gölü, ağır metal, anyonik deterjan, bor, fosfat

\section{Determination of Detergent, Phosphate, Boron and Heavy Metal Pollution in Adıgüzel Dam Lake (Denizli/Turkey)}

\begin{abstract}
This study was performed to determine of anionic detergent, phosphate, boron and heavy metal pollution in Adigüzel Dam Lake. The average concentrations of anionic detergent, phosphate, boron, copper, nickel, chromium and lead were found $0.235 \mathrm{mg} \mathrm{L}^{-1}, 0.009 \mathrm{mg} \mathrm{L}^{-1}, 0.659 \mathrm{mg} \mathrm{L}^{-1}, 0.0048 \mathrm{mg} \mathrm{L}^{-1}, 0.0170 \mathrm{mg} \mathrm{L}^{-1}, 0.0016 \mathrm{mg} \mathrm{L}^{-1}$, $0.0002 \mathrm{mg} \mathrm{L}^{-1}$, respectively. These values were compared with "Quality Criteria for Inland Water Resources by Class". Adıgüzel Dam Lake was classified as II. class (less contaminated water) in terms of anionic detergent parameter and I. class (uncontaminated water) in terms of phosphate, boron and heavy metal parameters.
\end{abstract}

Keywords: Adıüzel Dam Lake, anionic detergent, boron, heavy metal, phosphate

Orkide MİNARECİ (0000-0001-6746-6057), Manisa Celal Bayar Üniversitesi, Fen-Edebiyat Fakültesi, Biyoloji Bölümü, Manisa, Turkey

Murat ÇAKIR (0000-0002-5636-1636), Manisa Celal Bayar Üniversitesi, Fen Bilimleri Enstitüsü, Biyoloji Anabilim Dalı, Manisa, Turkey Sorumlu yazar/Corresponding Author: Orkide MINARECİ, orkide.minareci@cbu.edu.tr 


\section{GİRIŞ̧}

İnsanın yaşamının her döneminde yaşamsal faaliyetlerin gerçekleşebilmesi için su gerekli bir maddedir ve kendisi de bir yaşam ortamıdır. Bu nedenle suyun yaşam ortamında bulunması ve kalitesi çok önemlidir (Akın ve Akın, 2007). Dünyada nüfusun çok fazla artış1, endüstri ve teknolojinin hızlı gelişimi, insanlarda çevre koruma bilincinin oluşamaması gibi sebeplerle kullanılabilir suyumuz gittikçe azalmaktadır. İçme suyu kaynaklarımızın artarak kirlenmesi de kötü sonuçlar doğuran sorunlar yaşamamıza sebep olmaktadır (Dağlı, 2005; Atalık, 2006).

Başta sentetik deterjanlar olmak üzere yüzey aktif maddeler, temizlik madde formülasyonlarında dünyada yaygın bir şekilde kullanılarak, evsel ve endüstriyel atık sularla alıcı su ortamlarına önemli miktarda karbonlu atık madde olarak katılmaktadır. Genelde parçalanabilir yüzey aktif maddeler arıtma tesislerinde uzaklaştırılabilse de, indirgenmiş konsantrasyonlarda atı sularla akarsulara verilmektedir (Vural, 1983).

Akuatik ortamlarda fosfor, çok yönlü ve karmaşık kimyasal dengelerin anahtar elemanlarından biridir. Evsel atık sularda fosforun yaklaşık yarısı kullanılan deterjanların yapısındaki fosfattan gelir. Alıcı ortam suya fosforun $\% 91$ 'i evsel ve endüstriyel atıklardan gelirken, \% 9'u da tarımsal alanlardan gelmektedir (Egemen, 2011).

Bor bileşikleri yerüstü ve yeraltı sularında yaygın olarak bulunur. Dünyada bor konsantrasyonu, yeraltı sularında $>0.3 \mathrm{mg} \mathrm{L}^{-1}$ ve $<100 \mathrm{mg} \mathrm{L}^{-1}$, deniz suyunda $0.5-9.6 \mathrm{mg} \mathrm{L}^{-1}$, tatl1 sularda ise $0.01-1.5 \mathrm{mg}$ $\mathrm{L}^{-1}$ arasındaki değerlerdedir. Ayrıca kanalizasyon atık sularında bor konsantrasyonu 5-100 $\mathrm{mg} \mathrm{L}^{-1}$ arasındadır. Bor elementinin toksik limit değeri, bitkiler, hayvanlar ve insanlar için içme ve sulama sularında belirlenmiş olan limit değer ile aynı olarak atık sularda da $1.0 \mathrm{mg} \mathrm{L}^{-1}$ alınabilir (Kabay ve ark., 2006).

Selenyum, demir, mangan ve kobalt gibi elementler topraktan sulara karışmakta, magnezyum, potasyum ve kobalt elementleri havaya deniz suyundan geçmekte, çinko, bakır, kadmiyum, civa, antimon, arsenik, argon, kurşun, krom, selenyum gibi zehirli elementler atmosfere antropojenik faaliyetlerle karıştıktan sonra sulara ve toprağa karışmaktadır (Samsunlu, 1999).

Büyük Menderes Nehri'nin su kalitesinin belirlenmesi için yapılan araştırmada, Adıgüzel Baraj Gölü su kalite parametre değerleri düşük konsantrasyonlarda bulunmuştur (Küçük, 2007). Daha sonra çoğunlukla göldeki balık faunası üzerine çalışmalar yapılmıştır. Bıyıklı balık (Luciobarbus kottelati Turan, Ekmekçi, İlhan \& Engin, 2008) türünün Adıgüzel Baraj Gölü'ndeki populasyonunun bazı büyüme özellikleri saptanmıştır (Başıaçık ve ark., 2012). Yapılan diğer bir araştırmada, Adıgüzel Baraj Gölü'nde yayıllışı bulunan endemik tatlı su balığ1 Chondrostoma meandrense Elvira, 1987'nin bazı büyüme özellikleri araştırılmıştır (Gürleyen ve ark., 2012).

Ülkemizin tarım ve endüstri alanında en önemli üretim bölgelerinden olan Büyük Menderes Havzası, başta kirlilik olmak üzere su kaynakları ile ilgili problemlerle karşı karşıyadır. Tarımsal üretimin yanı sıra deri ve tekstil endüstrisi de havzada oldukça gelişmiştir (Çondur ve Cömertler, 2010).

Büyük Menderes Nehri, tarımsal açıdan önemli bir bölge olan Büyük Menderes Havzası'nın can damarıdır. Ama nehir, yerleşim yerlerinden kaynaklanan evsel atık sularla, sanayi kuruluşlarından kaynaklanan endüstriyel atık sularla, gübre ve pestisit kullanıldığ 1 için kimyasal maddeler içeren sulamadan dönen sularla ve jeotermal enerji santrali atık sularıyla kirletilmektedir. Bu nedenle Büyük Menderes'in su kalitesi bozulmakta ve kullanımı sinırlanmaktadır.

Adıgüzel Baraj Gölü, Büyük Menderes Nehri üzerinde bulunmaktadır. Göl suyunun kalitesinin bozulmasının, içme suyu, tarımsal kullanım ve balıkçılık açısından dolayısıyla da insan sağlığı açısından olumsuz etkiler yapacağı düşünülerek, bu çalışmada Adıgüzel Baraj Gölü'nün anyonik deterjan, fosfat, bor ve ağır metal kirliliğinin belirlenmesi amaçlanmıştır.

\section{MATERYAL VE YÖNTEM}

Adıgüzel Baraj Gölü, Büyük Menderes Nehri üzerinde, Denizli ve Uşak il sınırları içerisindedir. 
Baraj Gölü tarımsal sulamada, enerji üretiminde ve taşkın korumada kullanılmaktadır. Rakımı yaklaşık $430 \mathrm{~m}$ olan baraj gölü, 89600 hektarlık bir alanı sulamada kullanılırken, $62 \mathrm{MW}$ güç ile de yıllık 280 GWh'lık enerji üretmektedir (DSİ, 2017). $\mathrm{Su}$ örnekleri, ilk istasyon olarak belirlediğimiz baraj kapaklarının bulunduğu bölgeden ve ikinci istasyon olarak da, baraj gölünü besleyen önemli kaynaklardan birisi olan Hamam Çayı'nın göle etkisini belirlemek için, çayın baraj gölüne ulaştığ bölgeden alınmıştır. Örneklerin alındığı istasyonlar Şekil 1'de verilmiştir.

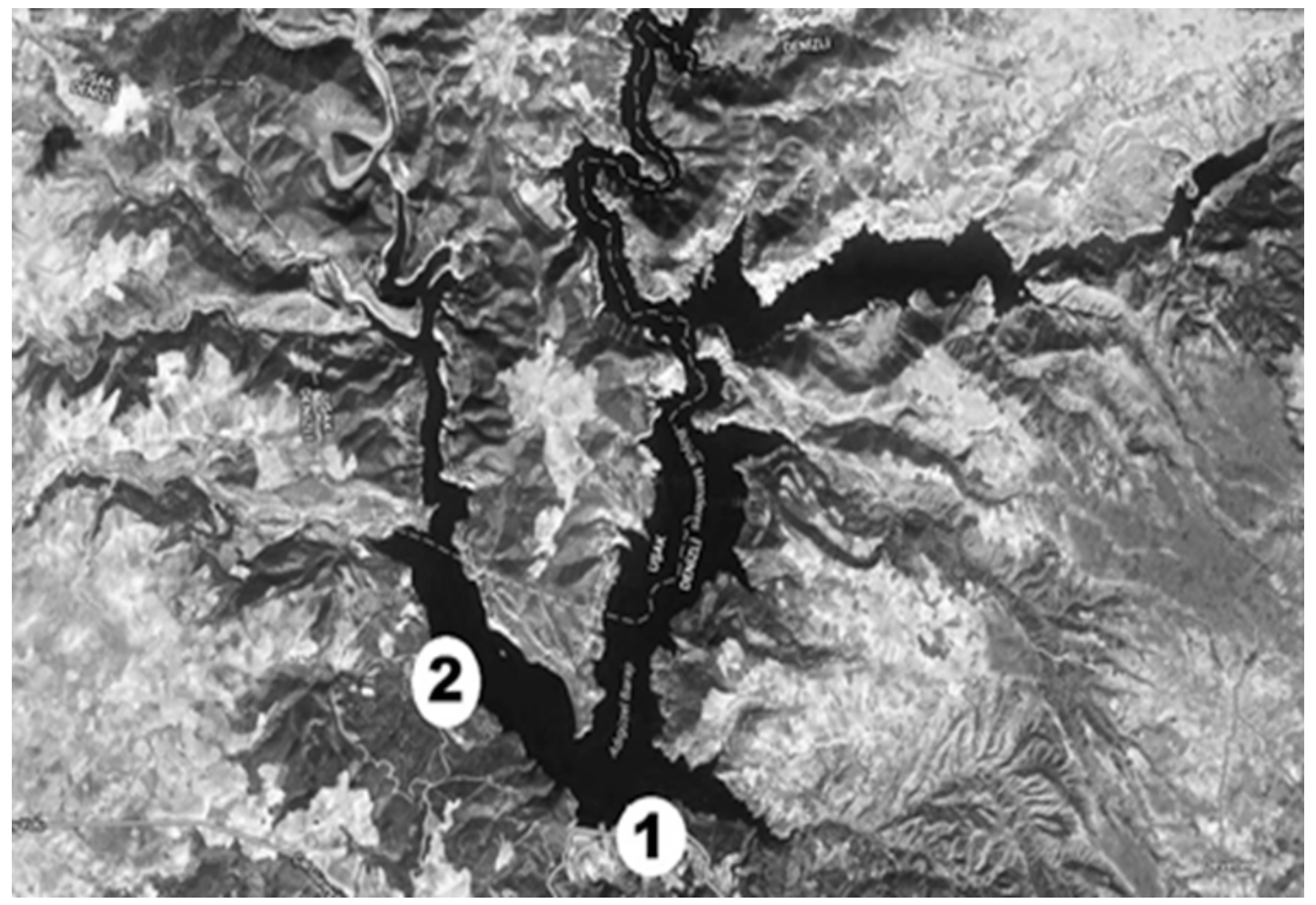

Şekil 1. Adıgüzel Baraj Gölü üzerindeki örnekleme istasyonları

Belirlenen istasyonlardan, her bir örneklemede üçer su örneği alınarak, aylık periyotlar halinde örnekleme yapılmıştır. Sicaklık, pH, çözünmüş oksijen, toplam çözünmüş madde ve iletkenlik parametreleri, TOA WQC (Water Quality Checker) - 20A marka su kalite parametreleri ölçüm cihazı ile arazide ölçülmüştür. Anyonik deterjan (Anonim, 1995), orto-fosfat fosforu (Parsons et al., 1984), bor (Hatcher and Wilcox 1950; Anonim, 2005) konsantrasyonları ise laboratuvarda spektrofotometre ile ölçülmüştür. Ağır metal analizleri de, ICP-MS cihazı kullanılarak gerçekleştirilmiştir.

\section{BULGULAR VE TARTIŞMA}

Adıgüzel Baraj Gölü’nde, ortalama sıcaklık 18.1 $( \pm 5.4){ }^{\circ} \mathrm{C}$, pH $8.6( \pm 0.5)$, çözünmüş oksijen $6.9( \pm 2.5)$ mg L ${ }^{-1}$, toplam çözünmüş madde $360( \pm 20.9) \mathrm{mg} \mathrm{L}^{-1}$ ve iletkenlik $100( \pm 0,0004) \mu \mathrm{S} \mathrm{cm} \mathrm{cm}^{-1}$ olarak bulunmuştur. Anyonik deterjan $0.07-0.403 \mathrm{mg} \mathrm{L}^{-1}$, fosfat $0.006-$ $0.018 \mathrm{mg} \mathrm{L}^{-1}$, bor $0.016-1.316 \mathrm{mg} \mathrm{L}^{-1}$, bakır $0.0004-$ $0.0049 \mathrm{mg} \mathrm{L}^{-1}$, nikel $0.0043-0.0396 \mathrm{mg} \mathrm{L}^{-1}$, krom 0.0009 - $0.0196 \mathrm{mg} \mathrm{L}^{-1}$, kurşun $0-0.0004 \mathrm{mg} \mathrm{L}^{-1}$ değerleri arasında değişmekte olup, bu konsantrasyonların aylık ortalama sonuçları Çizelge 1'de verilmiştir. 
Çizelge 1. Su örneklerindeki deterjan, fosfat, bor, bakır, nikel, krom ve kurşun konsantrasyonlarının aylık ortalamaları (mg L-1)

\begin{tabular}{|l|l|l|l|l|l|l|l|}
\hline Aylar & Deterjan & Fosfat & Bor & Bakır & Nikel & Krom & Kurşun \\
\hline Temmuz & 0.124 & 0.006 & 0.016 & 0.0012 & 0.0257 & 0.0015 & 0.0000 \\
\hline Ăgustos & 0.137 & 0.006 & 0.082 & 0.0025 & 0.0226 & 0.0014 & 0.0004 \\
\hline Eylül & 0.070 & 0.006 & 0.736 & 0.0008 & 0.0221 & 0.0017 & 0.0000 \\
\hline Ekim & 0.151 & 0.009 & 1.063 & 0.0005 & 0.0169 & 0.0011 & 0.0002 \\
\hline Kasım & 0.276 & 0.01 & 0.131 & 0.0013 & 0.0396 & 0.0016 & 0.0003 \\
\hline Aralık & 0.253 & 0.009 & 0.409 & 0.0031 & 0.0332 & 0.0011 & 0.0001 \\
\hline Ocak & 0.138 & 0.017 & 0.608 & 0.0006 & 0.0124 & 0.0009 & 0.0000 \\
\hline Şubat & 0.352 & 0.018 & 0.571 & 0.0025 & 0.0012 & 0.0014 & 0.0000 \\
\hline Mart & 0.284 & 0.009 & 0.731 & 0.0015 & 0.0043 & 0.0031 & 0.0002 \\
\hline Nisan & 0.287 & 0.013 & 0.961 & 0.0004 & 0.0140 & 0.0196 & 0.0002 \\
\hline Mayıs & 0.344 & 0.006 & 1.316 & 0.0009 & 0.0077 & 0.0167 & 0.0003 \\
\hline Haziran & 0.403 & 0.007 & 1.285 & 0.0049 & 0.0048 & 0.0074 & 0.0003 \\
\hline ORTALAMA & $\mathbf{0 . 2 3 5}$ & $\mathbf{0 . 0 0 9}$ & $\mathbf{0 . 6 5 9}$ & $\mathbf{0 . 0 0 4 8}$ & $\mathbf{0 . 0 1 7 0}$ & $\mathbf{0 . 0 0 1 6}$ & $\mathbf{0 . 0 0 0 2}$ \\
\hline
\end{tabular}

Her bir değer, üç tekrarlı 2 istasyondan alınan 3 örneğin $(n=18)$ ortalamasıdır. Standart hata $( \pm \mathrm{SH}<0.001)$

Ortalama olarak anyonik deterjan miktarı $0.235 \mathrm{mg} \mathrm{L}^{-1}$, fosfat miktarı $0.009 \mathrm{mg} \mathrm{L}^{-1}$, bor miktarı $0.659 \mathrm{mg} \mathrm{L}^{-1}$, bakır miktarı $0.0048 \mathrm{mg} \mathrm{L}^{-1}$, nikel miktarı $0.0170 \mathrm{mg} \mathrm{L}^{-1}$, krom miktarı $0.0016 \mathrm{mg} \mathrm{L}^{-1}$, kurşun miktarı $0.0002 \mathrm{mg} \mathrm{L}^{-1}$ bulunmuştur. Elde ettiğimiz tüm değerler, Su Kirliliği Kontrolü Yönetmeliği (Resmi Gazete, 2004) çerçevesinde Kıta İçi Su Kaynaklarının Sınıflarına Göre Kalite Kriterleri ile karşılaştıııldığında, Adıgüzel Baraj Gölü sularının çözünmüş oksijen parametresi ve yüzey aktif madde yönünden II. kalite, diğer tüm parametreler yönünden I. kalite su sınıfında olduğu görülmüştür. Adıgüzel Baraj Gölü’nün yerleşim yerlerine yakın bölgede olması nedeniyle ve deşarjların göle ulaştığı düşünülürse, evsel atık yüke bağlı olarak anyonik deterjan yükünün arttığı sonucuna varılabilir. Ortalama anyonik deterjan konsantrasyonumuz (0.235 $\left.\mathrm{mg} \mathrm{L}^{-1}\right)$, Avrupa Birliği su kalitesi kriterlerinde $\leq 0.3 \mathrm{mg} \mathrm{L}^{-1}$ olarak kabul edilen yüzey aktif madde konsantrasyonunun altındadir.

Adıgüzel Baraj Gölü su kalite verileri, Yerüstü Su Kalitesi Yönetmeliği (Resmi Gazete, 2012) Göl, Gölet ve Baraj Göllerinde Trofik Sınıflandırma Sistemi Sınır Değerleri'ne göre değerlendirildiğinde, gölün toplam fosfor parametresine göre oligotrofik göl sınıfına girdiği belirlenmiştir. Göllerde yapılan benzer çalışmalarda da göllerin trofik seviyeleri belirlenmiştir.

Samsun Kızılırmak Deltası'ndaki Balık Gölü su kalitesinin ve trofik seviyesinin belirlendiği çalışmada, özellikle denize yakın kıyılarında gölün aşırı ötrofikleştiği belirtilmiştir (Cüce ve ark., 2011).

Borçka Baraj Gölü (Artvin)'nde yapılan bir çalışmada su kalite verileri, Yerüstü $\mathrm{Su}$ Kalitesi Yönetmeliği Göl, Gölet ve Baraj Göllerinde Trofik Sınıflandırma Sistemi Sınır Değerleri ile karşılaştırılmış ve gölün mezotrofik göl olduğu saptanmıştır (Bilgin, 2015).

Işıktepe Baraj Gölü (Maden, Elazığg)'nde yapılan su kalitesi çalışması sonucunda, Yerüstü Su Kalitesi Yönetimi Yönetmeliği A ve $\mathrm{B}$ grubu parametrelerine göre baraj gölü "yüksek kaliteli" ve "az kirlenmiş" sınıflarında bulunmuştur (Küçükyılmaz ve ark., 2014).

Karakaya Baraj Gölü su kalitesinin incelendiği çalışmada, gölün mezotrof göllerin özelliğine sahip olduğu ve su ürünleri yetiştiriciliği için uygun olmadığ 1 sonucuna varılmıştır (Küçükyılmaz ve ark., 2017). 
Adıgüzel Baraj Gölü'nde daha önce yapılan çalışmalara bakıldığında özellikle barajın üzerinde kurulduğu Büyük Menderes Nehri'nde ve barajın bulunduğu bölgedeki iç sularda ilgili çalışmalar vardır.

Büyük Menderes Nehri'nde yapılan araştırmada, bor miktarının $0.33-6.41 \mathrm{mg} \mathrm{L}^{-1}$ arasında olduğu bulunmuş, özellikle yer altı termal su kaynaklarının bulunduğu bölgelerde bor konsantrasyonunun yüksek olduğu belirlenmiştir (Aydın ve Seferoğlu, 2000).

Yine Büyük Menderes Nehri yüzey suyunda yapılan bir çalışmada, nehre yapılan jeotermal atık su deşarjları nedeniyle bazı istasyonlarda bor konsantrasyonu $1.1 \mathrm{mg} \mathrm{L}^{-1}$ olarak saptanmış ve tarımsal sulama için kullanılan nehir suyunun direkt olarak tarımsal ürünlerin üretimini etkilediği belirtilmiştir (Akar, 2007).

Küçük (2007), Büyük Menderes Nehri su kalite ölçümlerini değerlendirdiği çalışmasında, nehrin ortalama bor değerini $0.6 \mathrm{mg} \mathrm{L}^{-1}$ saptamıştır.

Büyük Menderes Nehri'ni besleyen kaynakların üzerinde bulunan Işıklı Gölü ve Büyük Menderes Nehri'nin güney kolu olan Işıklı Çayı'nda yapılan çalışmada da, su örneklerinde anyonik deterjan konsantrasyonu Kıta İçi Su Kaynaklarının Sınıflarına Göre Kalite Kriterleri'ne göre değerlendirilmiştir. Işıklı Gölü ve Işıklı Çayı, yüzey aktif madde açısından II. Sınıf (az kirlenmiş su) olarak belirlenmiştir (Çakır ve Minareci, 2015).

Çivril Gölü (Işıklı Gölü) yüzey suyu kalitesinin değerlendirildiği başka bir araştırmada da, gölün bazı istasyonlarında özellikle yaz mevsiminde organik kirliliğin çok arttığı ve çözünmüş oksijen miktarının da oldukça azaldığı belirtilmiştir (Bulut ve ark., 2012).

Mumcular Barajı'nın fiziko-kimyasal özelliklerinin belirlendiği çalışmada, ortalama su sıcaklığı $20.7{ }^{\circ} \mathrm{C}$, pH 8.3, çözünmüş oksijen $7.3 \mathrm{mg} \mathrm{L}^{-1}$, fosfat $0.2 \mathrm{mg} \mathrm{L}^{-1}$, turbidite 7.4 NTU olarak belirlenmiştir. Kıta içi su kriterlerine göre Mumcular Baraj Gölü'nün II. sınıf özellik gösterdiği belirtilmiştir (Y1lmaz, 2004). Büyük Menderes Nehri'nde yapılan bu çalışmalarda elde edilen anyonik deterjan, fosfat ve bor değerleriyle bizim çalışmamızda elde ettiğimiz ortalama değerler karşılaştırıldığında değerlerin birbirine yakın olduğu görülmüştür.

Çalışmamızda elde ettiğimiz ortalama ağır metal konsantrasyonlarını, bazı göllerde yapılan ağır metal kirliliği çalışmalarında elde edilen konsantrasyonlarla karşılaştırdığımızda, genel olarak düşük olduğu görülmektedir.

Meriç Nehri Deltası'ndaki Gala Gölü ve gölü besleyen kaynaklardan alınan su ve sediment örneklerinin çoğunda kadmiyum, kurşun, mangan, kobalt ve bakır sınır değerlerin üzerinde çıkmıştır (Dökmeci ve Dinçer, 2005).

Karacaören II Baraj Gölü'nde yapılan kirlilik araştırmasında, krom, kadmiyum ve civa bütün mevsimlerde limit değerlerin altında bulunmuş, stronsiyumun ise suda en fazla biriken metal olduğu belirlenmiştir (Kır ve Tumantozlu, 2012).

$\mathrm{Su}$ ve sedimentte ağır metal birikiminin incelendiğ $i$ Kovada Gölü'ndeki çalışmada, suda en fazla bulunmuş olan demir tüm mevsimlerde, çinko 2005 ilkbahar ve 2006 kış mevsimlerinde, alüminyum 2005 yaz mevsiminde, nikel 2005 ilkbahar mevsiminde ve mangan 2006 kış mevsiminde belirlenmiş, kadmiyum, krom, bakır ve kurşun da tüm mevsimlerde ICP-OES' in analiz limit değerinin altında bulunmuştur (Kır ve ark., 2007).

Sapanca ve Abant Göllerinde yapılan bir çalışmada, Sapanca Gölü su ve sedimentinde ağır metal kirliliğinin trafikten, fosseptik atıklardan, tarımsal gübre ve ilaçlardan kaynaklandığ 1 , Abant Gölü'nde ise trafik ve fosseptik atık kaynaklı olduğu belirlenmiştir (Duman, 2005).

Van Gölü'nde yapılan ağır metal kirliliği araştırmasında, bakırın limit değerin altında, demir, mangan ve kurşunun limit değerlerin üzerinde, kadmiyum, çinko ve mangana göre de suyun I. ve II. kalitede olduğu bulunmuştur (Zengin, 2008).

Köyceğiz Gölü sedimentinde ağır metal fraksiyonlarının incelendiği araştırmada, mangan dışındaki metallerin risk oluşturmadığı veya düşük risk oluşturduğu, manganın ise aşırı derecede yüksek risk oluşturduğu tespit edilmiştir (Keskin ve ark., 2012).

Damsa Barajı (Nevşehir) yüzey suyu kalitesinin belirlendiği çalışmada, $\mathrm{pH}$, sıcaklık, çözünmüş oksijen ve amonyum parametreleri açısından baraj suyunun tarımsal sulamada kullanılabileceği, ağır metaller ve toksik madde açısından ise kullanıma uygun olmadığ belirtilmiştir (Kalıpcı ve ark., 2017). 


\section{SONUÇ}

Büyük Menderes Nehri üzerinde bulunan Adıgüzel Baraj Gölü, özellikle tarımda sulama için kullanılmaktadır. Tarım bölgesi olan Büyük Menderes Havzası'nda tarımsal sulama için kullanılan suyun kalite parametrelerinin bilinmesi ve izlenmesi sürdürülebilir bir tarım açısından önem taşımaktadır. Çalışmamızın sonucunda anyonik deterjan konsantrasyonları yüksek bulunmuştur. Adıgüzel Baraj Gölü’nün yerleşim yerlerine yakın bölgede olması nedeniyle ve deşarjların göle ulaştığı düşünülürse, evsel atık yüke bağlı olarak anyonik deterjan yükünün arttığı sonucuna varılabilir. Biyolojik parçalanabilirliği yüksek olan yüzey aktif maddeler kullanıldığında deterjan kirliliği önlenebilir. Deterjanlarda suyun sertliğinin giderilmesi için kullanılan sodyum tripoli fosfat kullanılmamalı, kirlilik yaratmayan başka maddeler kullanılmalıdır. Deterjanın mikroorganizmalarca yenmesi şeklinde olan biyolojik arıtım yapıldıktan sonra evsel atık sular alıcı ortama verilmelidir. Evsel atık su arıtım tesislerinde organik madde konsantrasyonu çok yüksek olduğundan,

\section{KAYNAKLAR}

Akar D, 2007. Potential boron pollution in surface water, crop and soil in the lower Büyük Menderes basin. Environmental Engineering Science, 24: 1273-1279.

Akın M, Akın G, 2007. Suyun önemi, Türkiye'de su potansiyeli, su havzaları ve su kirliliği. Ankara Üniversitesi Dil ve TarihCoğrafya Fakültesi Dergisi, 47(2): 105-118.

Anonim, 1995. Standard methods for the examination of water and wastewater. 19th Edition, APHA, AWWA, WPCF, Washington.

Anonim, 2005. Standard methods for the examination of water and wastewater. 21st Edition, APHA, AWWA, WEF, Washington.

Atalık A, 2006. Küresel ısınmanın su kaynakları ve tarım üzerine etkileri. Bilim ve Ütopya, 139: 18-21.

Aydın G, Seferoğlu S, 2000. Investigation of boron concentration of some irrigation waters used in Aydın region for plant nutrient and soil pollution. Proceedings of International Symposium on Desertification, 13-17 June 2000, Konya, 109-115.

Başıaçık S, Sarı HM, İlhan A, Ustaoğlu MR, 2012. Adıgüzel baraj gölü (Denizli) bıyıklı balık (Luciobarbus kottelati Turan, Ekmekçi, İlhan ve Engin, 2008) populasyonunun bazı büyüme özellikleri. Journal of Fisheries Sciences.com, 6(1): 32-38.

Bilgin A, 2015. Borçka Baraj Gölü su kalitesinin çok değişkenli istatistiksel yöntemle değerlendirilmesi. Celal Bayar Üniversitesi Fen Bilimleri Dergisi, 11(2): 287-293.

Bulut C, Atay R, Uysal K, Köse E, 2012. Çivril Gölü (Işıklı Gölü) yüzey suyu kalitesinin değerlendirilmesi. Anadolu Üniversitesi Bilim ve Teknoloji Dergisi - C Yaşam Bilimleri ve Biyoteknoloji, 2(1): 1-8. ortamda hızlı bir şekilde çoğalan mikroorganizmalar deterjanları kuvvetlice absorbladığında, deterjan konsantrasyonu azaltılabilecektir. Böylece deterjan miktarları kaynağında kontrol edilecek, alıcı sularda canlılar için toksik etkiler azalacaktır. Gölde fosfat, bor ve ağır metal konsantrasyonlarının kriter değerlerden düşük olması, gölün endüstri bölgesine ve termal suların çıktığı bölgeye uzak olması nedeniyle beklenen bir sonuçtur. $\mathrm{Bu}$ da göl sularının özellikle tarımsal sulama için kullanımının bu parametreler açısından uygun olduğunu göstermektedir.

\section{TEŞEKKÜR}

$\mathrm{Bu}$ çalışma Manisa Celal Bayar Üniversitesi Bilimsel Araştırma Projeleri Koordinasyon Birimi tarafindan 2012-099 numaralı proje kapsamında desteklenmiş Yüksek Lisans Tezinden üretilmiştir. Ayrıca ağır metal ölçümleri de 2013-139 numaralı proje kapsamında yapılmıştır. Projeleri destekleyen Manisa Celal Bayar Üniversitesi Bilimsel Araştırma Projeleri Koordinasyon Birimine teşekkür ederiz.

Cüce H, Bakan G, Akıncı H, 2011. Balık Gölü (Kızılırmak Deltası, Samsun) su kalitesinin konumsal analizi. TMMOB (Türk Mühendis ve Mimar Odaları Birliği) Coğrafi Bilgi Sistemleri Kongresi, 31 Ekim - 4 Kasım 2011, Antalya.

Çakır M, Minareci O, 2015. Işıklı Gölü ve Işıklı Çayı'nda (ÇivrilDenizli) deterjan, fosfat ve bor kirliliğinin araştırılması. İstanbul Üniversitesi Su Ürünleri Dergisi, 30(1): 23-34.

Çondur F, Cömertler N, 2010. Çevre kirliliği ve yoksulluk ilişkisi: Büyük Menderes Havzası Örneği. Ekonomi Bilimleri Dergisi, 2(2): 1309-8020.

Dağlı H, 2005. İçme suyu kalitesi ve insan sağlığına etkileri, bizim İller. İller Bankası Aylık Yayın Organı, 3: 16-21.

Devlet Su İşleri Genel Müdürlüğü, 2017. Adıgüzel Barajı. http:// www2.dsi.gov.tr/baraj/detay.cfm?BarajID=153 (Erişim tarihi: 19 A ğustos, 2017).

Dökmeci AH, Dinçer AR, 2005. Gala gölü ve gölü besleyen su kaynaklarında ağır metal kirliliğinin araştırılması. Trakya Üniversitesi Fen Bilimleri Enstitüsü, Yüksek Lisans Tezi, 122 s.

Duman F, 2005. Sapanca ve Abant Gölü su, sediment ve sucul bitki örneklerinde ağır metal konsantrasyonlarının karşılaştırmalı olarak incelenmesi. Ankara Üniversitesi Fen Bilimleri Enstitüsü, Doktora Tezi, $227 \mathrm{~s}$.

Egemen Ö, 2011. Su Kalitesi. 7. Bask1, Ege Üniversitesi Su Ürünleri Fakültesi, Yayın No:14, Bornova - İzmir, 90-91.

Gürleyen N, İlhan A, Başıaçık S, Ustaoğlu MR, Sarı HM, 2012. Adıgüzel baraj gölü'ndeki kababurun balığı (Chondrostoma meandrense Elvira, 1987)'nın bazı büyüme özellikleri. Ege Üniversitesi Su Ürünleri Dergisi, 29(3): 123-126. 
Hatcher JT, Wilcox LV, 1950. Colorimetric determination of boron using. Analytical Chemistry, 22(4): 567-569.

Kabay N, Y1lmaz I, Bryjak M, Yüksel M, 2006. Removal of boron from aqueous solutions by ion exchange-membrane hybrid process. Desalination, 198: 74-81.

Kalıpcı E, Cüce H, Toprak S, 2017. Damsa Barajı (Nevşehir) yüzey suyu kalitesinin coğrafi bilgi sistemi ile mekansal analizi. Karaelmas Fen ve Mühendislik Dergisi, 7(1): 312-319.

Keskin F, Demirak A, Şahin Y, 2012. Köyceğiz Gölü sedimentinde ağır metal fraksiyonlarının incelenmesi. 26.Ulusal Kimya Kongresi, 1-6 Ekim 2012, Muğla.

Kır İ, Özan ST, Tuncay Y, 2007. Kovada Gölü’nün su ve sedimentindeki bazı ağır metallerin mevsimsel değişimi. Ege Üniversitesi Su Ürünleri Dergisi, 24(1-2): 155-158.

Kır İ, Tumantozlu H, 2012. Karacaören-II Baraj Gölü'ndeki su, sediment ve sazan (Cyprinus carpio) örneklerinde bazı ağır metal birikiminin incelenmesi. Ekoloji Dergisi, 21(82): 65-70.

Küçük S, 2007. Büyük Menderes Nehri su kalite ölçümlerinin su ürünleri açısından incelenmesi. Adnan Menderes Üniversitesi Ziraat Fakültesi Dergisi, 4: 7-13.

Küçükyılmaz M, Örnekci GN, Uslu AA, Özbey N, Şeker T, Birici N, Yıldız N, Koçer MAT, 2014. Işıktepe Baraj Gölü (Maden, Elazığ) kıyı bölgesi fizikokimyasal su kalitesi üzerine ilk bulgular. Yunus Araştırma Bülteni,14(2): 55-63.
Küçükyılmaz M, Uslu G, Birici N, Örnekçi NG, Yıldız N, Şeker T, 2017. Karakaya Baraj Gölü su kalitesinin incelenmesi. Yunus Araştırma Bülteni, 17(2): 145-155.

Parsons TR, Matia Y, Lalli CM, 1984. A manual of chemical and biological methods for sea water analysis. Pergamon Press, New York, $173 \mathrm{p}$.

Resmi Gazete, 2004. Su Kirliliği Kontrolü Yönetmeliği. Tarih 31.12.2004, Say1 25687.

Resmi Gazete, 2012. Yerüstü Su Kalitesi Yönetmeliği. Tarih 30.11.2012, Say1 28483.

Samsunlu A, 1999. Çevre Mühendisliği Kimyası. Sam-Çevre Teknolojileri Merkezi Yayını, İstanbul, 394s.

Vural N, 1983. Sentetik deterjanlar. Bilim ve Teknik Dergisi, 165(14): 9-11.

Yılmaz F, 2004. Mumcular Barajı (Muğla-Bodrum)'nın fizikokimyasal özellikleri. Ekoloji Dergisi, 13(50): 10-17.

Zengin O, 2008. Van Gölü ve gölü besleyen kaynaklarda ağır metal kirliliğinin araştırılması. Gazi Üniversitesi Fen Bilimleri Enstitüsü, Yüksek Lisans Tezi, 104 s. 